\title{
The Use of the Ant Algorithm in the Audit Planning of Multi-Branch Organizations
}

\author{
Majed Alsolamy ${ }^{1}$, Gihan Taha ${ }^{2}$ \\ ${ }^{1}$ Department of Administration, University of Tabuk, Tabuk, Saudi Arabia \\ ${ }^{2}$ Department of Accounting, University of Tabuk, Tabuk, Saudi Arabia \\ Email: malsolamy@ut.edu.sa,jissa@ut.edu.sa
}

How to cite this paper: Alsolamy, M., \& Taha, G. (2021). The Use of the Ant Algorithm in the Audit Planning of Multi-Branch Organizations. iBusiness, 13, 187-209. https://doi.org/10.4236/ib.2021.134012

Received: October 8, 2021

Accepted: December 27, 2021

Published: December 30, 2021

Copyright ( 2021 by author(s) and Scientific Research Publishing Inc. This work is licensed under the Creative Commons Attribution International License (CC BY 4.0).

http://creativecommons.org/licenses/by/4.0/

\begin{abstract}
The study aims to define the important variables to be considered by auditors during the planning phase in multi-branch organizations. The objective of the research determines the possibility of using the ant algorithm as an AI tool suited to plan the audit and identify the audit schedule. The data is based on a survey to collect data to explore the most important factors that influence audit planning. The findings of the study indicate that: 1 ) the most important variables in audit planning in multi-branch organizations are risk and materiality; 2) the application of AI methods helps reduce bias and judgment of auditors.
\end{abstract}

\section{Keywords}

Audit Planning, Audit Risk, Ant Algorithm, Multi-Branch Organization

\section{Introduction}

Planning is a process that encompasses the whole audit period. It includes the development of a general strategy and detailed procedures suited to identify the audit's general objectives, scope, cost, timeline, and appropriate timing and the branches and sectors to be audited. This aimed to ensure that it fits with the required scope of work and any changes taking place in the prevailing conditions while the work is being conducted.

In an audit of the financial statements of a company with operations in multiple branches or business units, the auditor should determine the extent to which audit procedures should be performed at selected branches or business units to obtain sufficient appropriate evidence to obtain reasonable assurance about whether the financial statements are free of material misstatement. This includes determining the branches or business units at which to perform audit procedures, as well as the nature, timing, and extent of the procedures to be performed at those 
individual branches. Audits are planned and implemented in organizations based on auditing standards and on regulatory and legislative requirements.

The audit planning phase includes:

1) The preliminary examination and study of the economic unit under audit;

2) The calculation of the audit's cost;

3) The evaluation of the control environment;

4) The determination of the level of materiality and risk levels;

5) The preparation of an audit plan proposal to identify those sectors or branches that will be subjected to greater scrutiny;

6) The selection of engagement team members with appropriate levels of capabilities and competencies;

7) The preparation of the schedule for performing the audit.

Professional accounting and auditing organizations take great care in the planning phase due to its importance in increasing audit efficiency and effectiveness. This interest is reflected in the issuance of several standards and guidelines. Some academics have also focused on audit planning. By analyzing those studies, we found that:

1) Audit planning is still dependent on the auditor's personal judgment and experience;

2) Most studies were focused on audit planning in relation to defining the plan components and items and did not adopt a scientific method or approach;

3) Scarcity of studies provided an audit planning model based on Artificial Intelligence (AI) technological methods;

4) The ant algorithm helps in planning audits and in determining the audit schedule with a greater degree of accuracy than traditional methods;

5) Previous research was mostly dependent on the use of critical trail maps or PERT networks.

The main questions of this study: 1) Do auditors rely on personal judgment and professional experience because there is no scientific method or approach suited to aid in effective audit planning? 2) Does use the ant algorithm impact on the external audit planning effectiveness?

\section{Literature Review}

\subsection{External Audit Planning}

Planning is essential for any task to be performed. Audit planning includes developing the overall engagement strategy and the audit program, and includes planned procedures suited to evaluate and respond to risks of material misstatements. Planning is not a discrete phase of an audit but rather a continual and iterative process throughout the audit engagement. The audit plan is more detailed than the overall audit strategy and includes the nature, timing and extent of audit procedures to perform by team members in order to obtain sufficient evidence to reduce audit risk to an acceptable low level (Leung, 2015). During this stage, the auditor indicates the two essential elements of materiality and au- 
dit risks. Both elements help in preparing the audit schedule and estimated timetable.

Professional organizations engage in audit planning. Thus, the US external audit standards indicate that "the auditor must develop an adequate plan for the work and supervision of the assistants" (AICPA, 2019). The (IFAC, 2009) indicates appropriate audit planning aids in ensuring that sufficient and adequate attention is giving to important audit areas, that any potential problems are identified and solved in a timely manner, that the audit is organized and managed correctly, and that the work is properly distributed, directed, and supervised depending on audit size and complexity.

The guideline to the practice of auditing in the Kingdom of Saudi Arabia also indicates that the planning phase includes the development of the audit's general strategy and the definition of the comprehensive audit plan that proceeds and guides the preparation of a detailed audit program (SOCPA, 2018).

Factors that are relevant developing the audit plan in multi-branches organization:

1) The factors affecting the industry in which the organization operates, such as economic conditions, technological changes, laws, and regulations, etc.;

2) The nature and amount of assets, liabilities, and transactions executed at the branch "significant unusual transactions";

3) The materiality and the specific risks associated with the branch;

4) The type and nature of evidence related to the effectiveness of the internal financial report control system;

5) The frequency, timing, and scope of monitoring activities by the company or others at the branch;

6) Any factors related to the organization itself, such as operating characteristics, financial structure, recent changes that may affect the operations of the facility or the internal control of financial reports, deficiencies in internal control, organizational and legal aspects, and the degree of complexity of the organization's operations.

Bonner (1990) confirmed the impact of the auditor's previous experience with the client's business and of his/her personal judgment on evaluating internal control systems and making decisions related to planning, while Ashton (1991) indicated that experience with the client's work does not affect the prediction of the recurrence of errors.

Solomon (1996) sought to examine the impact of auditor experience with the client's industry and the nature of his/her business on the reoccurrence of errors and on the planning for the sequence of audit tests. The results of this study indicate that previous experience plays an important and influential role in the accuracy of the auditor's evaluation of the possibility of recurrence and, as such, determines the scope of the audit tests. Taylor's (2010) empirical research indicates the effect of specialization in auditing a specific sector on the external auditors' evaluations of the inherent risks and on the degree of reliability of those evaluations. 
Furthermore, Wright (1997) aimed at studying the behavioral impact of previous experience with the nature of the client's business on making decisions related to audit planning. The results indicate that such experience influences the accuracy of the predictions related to the possibility of errors and the implementation of analytical procedures. The author also found that evaluating the audit's risks or determining its scope requires the availability of other factors other than experience with the nature of the client's business. (Bani-Ahmed \& Al-Sharairi, 2014) identified audit planning as an essential element suited to avoiding any potential issues and applying comprehensive quality concepts to achieve long-term strategic goals.

Meliyev (2017) examined external audit planning as an essential element suited to facilitate and successfully complete an audit, and the audit plan as a mechanism that enables the clarification of the audit's nature, timing, and scope in accordance with auditing standards. The results indicate that the first step involved in audit planning is the development of a framework for the required financial reports and for any specific ones related to the nature of the sector to which the organization belongs and to the organization's branches, if any. The study shows that the subsequent risk assessment, performed in line with the work environment and the size of the organization, helps in setting the plan more accurately.

Karapetrovic (2010) also highlighted the importance of relying on a systematic approach when planning an audit by defining a policy and general objectives, and then transforming the policy into a program that shows the objectives of partial or individual audits.

By analyzing previous studies, we found that most of them had focused on the impact of the auditor's experience on the decisions he/she had made in relation to audit planning. The use of quantitative methods had aided in rationalizing the auditor's personal judgment. Many studies had also focused on risk analysis as an introduction to external audit planning and implementation. Thus, during the audit planning phase, an auditor should consider the nature, level, and timing of the work, and prepare a written audit program.

To this end, the auditor should consider the following aspects:

1) The nature of the business and sector of the organization to be audited;

2) The policies and procedures applied by the organization;

3) The estimated level of any inherent and control risks;

4) The materiality of the branch or item under audit;

5) Other fields that may require attention and any potential occurrences of fraud and error.

We believe that one of the most important decisions an external auditor makes when defining an audit program is linked to the determination of the timing and duration of the implementation of each audit. This is especially critical in multi-branch organizations, where the timing of financial statement audits and branch operations is one of the important factors that may lead to reducing the risks 
and increasing the effectiveness of audits. Timing requires the following preliminary steps:

1) Determining the timing to audit each branch: the audit manager sets the time budget to determine the period during which the audit should be conducted, and the time required to implement each audit stage. The auditor relies on his/her personal judgment and previous experience to consider the internal and external changes that may affect the branch business;

2) Determining the timing of the audit tests: the auditor chooses the timing related to conducting the control and verification tests on the basis of the audit risk level previously specified for each assertion (Johnstone \& Bedard, 2003). Then, the timing of the implementation of verification tests is determined by whether the internal control system is found to be effective;

3) Determining the timing of the audit procedures: the timing of the audit procedures is determined, and whether they will be implemented at fiscal year-end or earlier.

Therefore, the external auditor should give special attention to the timing of the audit tests and procedures. While many extant studies concentrated on this aspect, this study focuses on the auditor's decision to start the audit process at a specific date, and on the audit schedule in multi-branch organizations.

\subsection{The Ant Algorithm}

In recent years, many developments in computer science and AI have been made based on observations of real-life situations, simulating cognitive skills, and providing a competitive advantage to users. The basis of this science is bioinformatics, which tracks those developments in cognition and AI that attempt to replicate the processes of the human mind in a computer environment. Accounting and auditing offices use AI in their auditing and consulting functions, where it brings many benefits-such as saving time (PWC, 2019), increasing the level of accuracy, and improving the quality of the service provided to the client. Major accounting and auditing offices make huge investments in AI, as it is used to review general ledgers and tax obligations, prepare work documents, perform accurate analyses of numeric and text data, review unstructured data, and make decisions (Issa, 2016). This also includes applications of AI in identifying high-risk audit areas and uncovering unusual items (Bowling, 2019).

Beni and Wang first introduced the term "swarm intelligence" in 1989, in reference to decentralized cooperative behaviors and self-organizing systems that reach unified general behaviors. An example of such systems found in nature is represented by ant colonies (Castro, 2006).

In 1992, the Ant algorithm was first introduced by Italian scientist Marco Dorigo as a probabilistic method suited to reach the optimal solution in computational problems. The idea of the artificial Ant algorithm revolves around simulating the behavior of an ant colony by means of "simulated ants" that move around a map that expresses the problem to be solved (Wikipedia, 2021).

In practice (Vizine et al., 2005), ants wander randomly until they find food 
and then return to their nest. During the return trip, they secrete a stigmergic substance. Other ants no longer move randomly but follow the trail of this substance in their return journey. This behavior inspired the scientists to present the Artificial ant algorithm, whereby a group of artificial ants cooperates to solve a problem through information exchange (Dorigo \& Gambardella, 1997).

Ant colonies present many potentially beneficial behavioral characteristics, such as performing complex tasks without central coordination, self-organizing, and the ability to tolerate disruptions in the surrounding environment (Coppin, 2004).

Many studies show that the Ant algorithm not only produces more accurate results but is also more efficient than many other methods (Gao, 2016).

Some of the main features of the artificial Ant algorithm, which are taken from the natural model, are (Jones, 2006):

1) Artificial ants exist in groups of cooperating individuals who are in direct contact with a secreted substance;

2) Artificial ants perform successive motions to find the shortest path from the starting point to the assignment one (the optimal solution to the problem);

3) The Ant algorithm relies on the available information to find the best solution;

4) The Ant algorithm has additional capabilities not available in its natural counterpart;

5) In artificial ant systems, every ant can find a solution to the problem, but the optimal one is only reached through the comprehensive cooperation of the ant colony (Erdinc, 2017);

6) The Ant algorithm is a suitable alternative to traditional clustering ones because it can automatically detect the number of clusters (Jafar \& Sivakumar, 2010).

The Ant algorithm is used to solve both dynamic and static problems, such as (Bertelle et al., 2003):

- Finding the shortest route to be followed by a ship to visit a set of cities;

- Determining quadratic functions suited to minimize labor costs;

- Distributing work schedule on machines;

- Allocating production processes at intervals of time;

- Dealing with transport disorder problems (Pop et al., 2009);

- Determining the shortest route for calls over communications networks;

- Analyzing financial data and classifying them into homogeneous groups.

\subsection{Basic Ant Algorithm}

Ant movements depend on a set of simple probabilistic equations. The following equation represents the line to be followed:

$$
P=\frac{\tau(r, u)^{\alpha} \times \pi(r, u)^{\beta}}{\sum_{k} \tau(r, u)^{\alpha} \times \pi(r, u)^{\beta}}
$$

where $\tau(r, u)$ refers to the density of the hormone on the line between the $r$ 
and $u$ nodes, which is a heuristic function that represents the reciprocal of the measured distance of the line, whereas $\alpha$ represents the hormone weight and $\beta$ represents the reciprocal of the weight.

The ants' route is determined by the following equation, which shows the hormone value on each line:

$$
\Delta \tau_{i j}^{k}(t)=\frac{Q}{L^{k}(t)}
$$

where $K$ represents a line that has not been visited and $Q$ is a fixed variable that is determined according to the nature of the problem under study.

And to increase the hormone (the substance that is secreted) during the tour on each line through the equation:

$$
\tau_{i j}(t)=\tau_{i j}(t)+\left(\tau_{i j}^{k}(t)+P\right)
$$

where $P$ is a constant that ranges between 0 and 1 . Pheromone evaporation is calculated by the following equation:

$$
\tau_{i j}(t)=\tau_{i j}(t) \times(1-P)
$$

When the route is completed, the algorithm is applied through a computer program, subject to the following requirements:

1) The existence of a community of artificial ants (agent);

2) A network representing the environment in which the ants operate;

3) The ants move from one node to another along weighted lines to reach the optimal solution.

Interviews conducted with several audit managers in major auditing offices in the Kingdom of Saudi Arabia to understand the steps involved in audit program planning and in distributing auditors in multi-branch organizations. The results indicated that the auditors followed the following procedures when planning audit:

1) Reviewing previous audit reports;

2) Studying the changes and events affecting the organization;

3) Examining and studying periodic financial statements;

4) To identify the risks of any material misstatements according to the office equations or programs;

5) Determined the relative importance as a percentage of the total assets or net profit and then determined the volume of evidence to be collected;

6) Holding discussions with the managers and employees of the organization;

7) Studying the laws, regulations, and instructions applicable to the organization;

8) Coordinating and supervising the audit team members;

9) Setting the audit implementation schedule or timeline.

\section{Data and Methodology}

In collecting data for this study, we relied on the survey method. The question- 
naire was sent electronically to the major offices and institutions involved in the audit process in the Kingdom of Saudi Arabia.

The questionnaire was structured as follows:

- The interviewee's personal data (gender, profession, and number of years of experience);

- The 10 factors affecting the audit planning in multi-branch organizations and their relative effects, as follows: the size and nature of the organization and its branches, the characteristics and size of the branch operations, experience and personal judgment, branch internal audit reports, previous external audit reports, professional judgment in team guidance, resources available to perform an audit, estimated risks associated with the branch operations, the materiality of branch operations.

Personal and demographic characteristics of the respondents: 1) distribution of the sample in terms of gender. The number of males was 51, representing $77.3 \%$ of the total, while the number of females was 15 , representing $22.7 \%$; 2 ) distribution of the sample in terms of position. The positions held by the respondents varied, with the largest percentages being held by "internal audit manager" and "internal auditor" (30.3\% each). This was followed by "chartered accountant or financial controller", "financial market institutions inspector", and "assistant auditor" (9.1\% each), and by "financial manager" (7.6\%), while the less represented position was "external auditor" (4.5\%); 3) years of experience of the respondents. By taking the centers of the categories, the arithmetic mean of the years of experience was found to be 7.9 years, with a standard deviation of 3.4 years, which indicates a high level of respondent experience.

Descriptive analysis of the personal characteristics of our sample: Table 1 shows the frequencies and percentages of the distribution of the study sample according to their personal characteristics (gender, occupation, and years of experience).

We used the G-Power software to select our sample size according to the following criteria:

- The type of analysis used (correlation), which was mainly focused on testing the relationships between variables;

- Effect size: $\rho=0.38$, as the medium effect size was considered based on the following effect size conventions: small $=0.10-0.29$, medium $=0.30-0.49$, and large $=0.50-1.00$;

- Alpha a (the error of the first type) $=0.05$ (the probability of rejecting the null hypothesis while it is true), i.e., with a confidence degree of 0.95 , as the degree of confidence is $1-\alpha$;

- The test power $(1-\beta)=0.95$, where $\beta$ represents the error of the second type (the probability of accepting the null hypothesis, which is false). The following figure shows the indicators that were used in the G-Power software and the appropriate sample size according to the previous conventions:

As shown in Figure 1, the software identified the appropriate sample size as 66. 
Table 1. Distribution of the study sample according to personal characteristics.

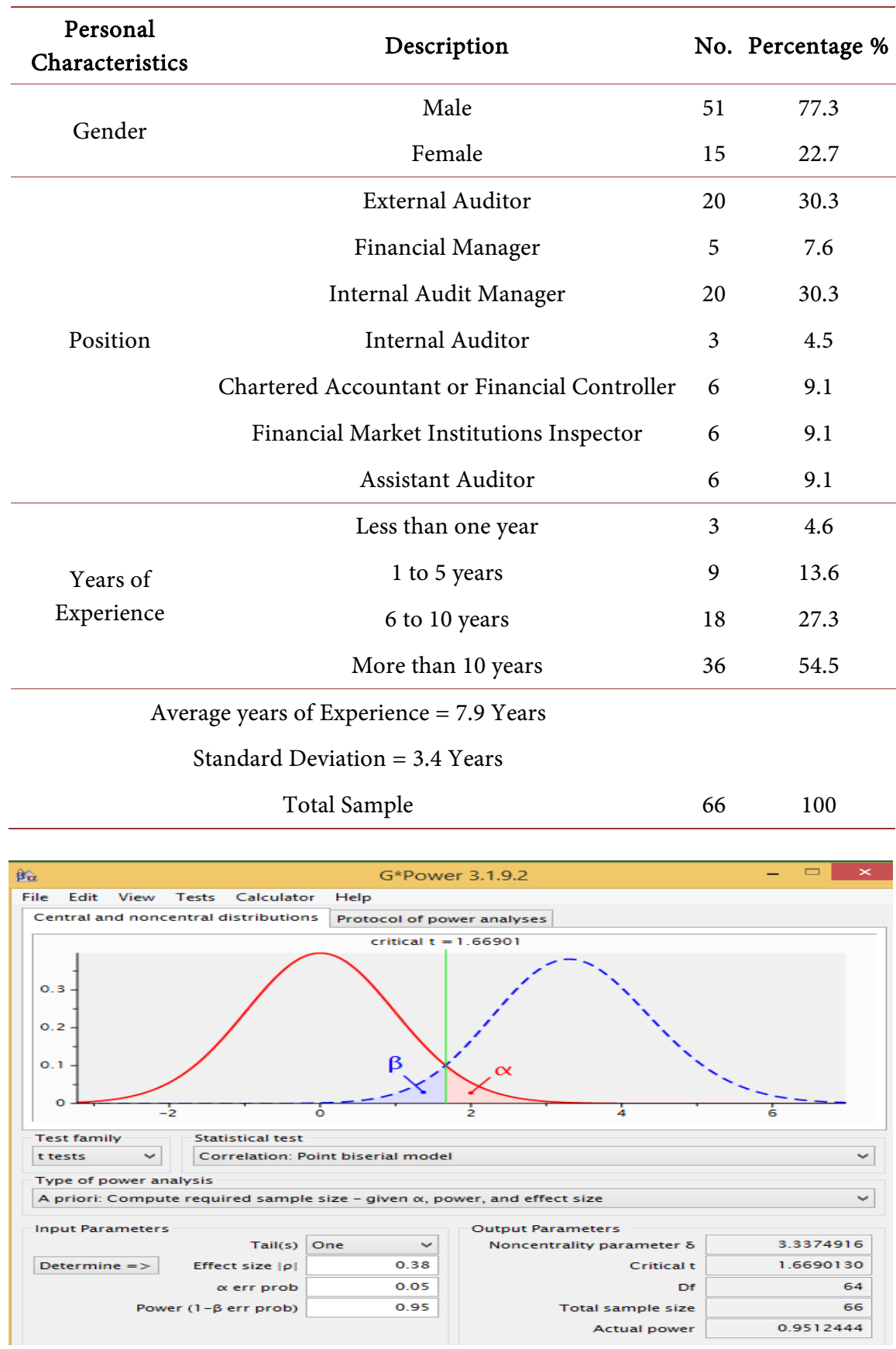

Figure 1. Define the appropriate sample size (G-Power software).

Our field study was aimed at testing the validity of the following hypotheses:

- H1. There is a statistically significant relationship between audit planning and the auditor's personal judgment and experience;

- H2. There is a statistically significant relationship between audit planning and the auditor's assessment of the materiality of the branch operations;

- H3. There is a statistically significant relationship between audit planning and the estimated risks associated with the branch operations; 
- H4. There is a statistically significant relationship between audit planning and the audit cost.

\subsection{Statistical Methods Used to Analyze the Survey Questionnaire Data}

We used a descriptive statistical method to describe the data and show the degree to which our sample had responded to the survey questions. Analytical statistics were also used to test our hypotheses using the Statistical Package for the Social Sciences (SPSS). When designing the survey questions, we used the following five-point Likert Scale to determine the effect of each factor on audit planning in multi-branch organizations:

\begin{tabular}{ccccc}
\hline Very Low & Low & Neutral & High & Very High \\
\hline 1 & 2 & 3 & 4 & 5 \\
\hline
\end{tabular}

After taking the weighted average of the responses, this range was divided into degrees of approval, as the overall range $(5-1=4)$ was divided into five categories, each category had a width of $4 / 5=0.80$, as follows:

\begin{tabular}{ccccc}
\hline Very Low & Low & Neutral & High & Very High \\
\hline 1 to 1.79 & 1.80 to 2.59 & 2.60 to 3.39 & 3.40 to 4.19 & 4.20 to 5 \\
\hline
\end{tabular}

And the following statistical methods were used:

- Cronbach's alpha coefficient: the stability coefficient of the responses, which ranges between zero and one. The closer to one, the greater the credibility and stability and vice versa. Therefore, the statistically lowest acceptable threshold for this coefficient is $60 \%$. If it is lower, there is weak credibility;

- Internal consistency test: measured by the correlation coefficient between each of the questionnaire statements, and the dimension or axis to which that statement belongs. A positive and statistically significant correlation indicates internal consistency between the statements and the axes to which it belongs;

- Confirmatory factor analysis CFA: to ensure that the statements measure the study axes;

- $\mathrm{T}$ test on the medium value: it requires determining the test value, which was represented by the average value of the Likert scale, which was 3. Considering this, the null hypothesis and the alternative hypothesis were formulated as follows:

\begin{tabular}{cl}
\hline Null hypothesis: & $\mathrm{H}_{0}: \mu \leq 3$ \\
Alternative hypothesis: & $\mathrm{H}_{1}: \mu>3$ \\
\hline
\end{tabular}

The rule of judgment is based on the calculated level of significance. If it was found to be lower than 0.05 , and the value of $\mathrm{T}$ was found to be positive, we could reject the null hypothesis and accept the alternative one, and if the level of 
significance was found to be greater than or equal to 0.05 , or the value of $\mathrm{T}$ was found to be negative, we could not reject the null hypothesis.

- Measures of central tendency such as: arithmetic mean, frequencies, and percentages, in order to describe the opinions of the study sample, and to determine the importance of the statements in the survey questionnaire, as well as the standard deviation to indicate the degree to which the answers were dispersed in relation to their arithmetic mean.

- Mann-Whitney test: to compare the responses of two sub-samples (males and females). The null and alternative hypothesis can be formulated as follows:

The null hypothesis H0: M1 = M2, meaning that the average ranks of the first category are equal to those of the second.

Alternative hypothesis $\mathrm{H} 1: \mathrm{H} 0: \mathrm{M} 1 \neq \mathrm{M} 2$, meaning that the average ranks of the first category are not equal to those of the second.

The criterion was based on the calculated Sig. level. If it was found to be lower than 0.05 , we could reject the null hypothesis and accept the alternative hypothesis, and vice versa.

- Kruskal-Wails test: used to compare the responses of more than two study sub-samples (professional positions, years of experience). The null and alternative hypothesis can be formulated as follows.

The null hypothesis $\mathrm{H} 0: \mathrm{M}_{\mathrm{n}}=\ldots=\mathrm{M} 2=\mathrm{M} 1$, meaning that the average ranks of the first category are equal to those of the second, the third, etc.

Alternate hypothesis H1: There is at least a pair of categories with different average ranks.

The criterion was based on the calculated Sig. level. If it was found to be lower than 0.05 , we could reject the null hypothesis and accept the alternative one, and vice versa.

- Simple correlation analysis: based on Pearson's linear correlation coefficient. The degree, direction, and significance of the simple correlation between the study variables were determined through this relationship;

- Simple regression analysis: to test the effect of the independent variables on the audit planning dependent variable.

The most important methods used in regression analysis are as follows:

- R2 corrected coefficient of determination: the square of the multiple correlation coefficient, which shows the percentage of changes in the dependent variable that are explained by the independent ones;

- F test: one of the methods of Analysis of Variance (ANOVA) that tests the significance of the regression model. We relied on the calculated level of significance sig. as a criterion. If it was found to be lower than 0.05 , the significance of the model could be accepted;

- T test: to test the significance of the estimated parameters (i.e., the regression constant and the regression parameters). We relied on the calculated level of significance Sig. as a criterion. If it was found to be lower than 0.05 , the significance of the parameters could be accepted;

- Durbin-Watson test: to test the degree of autocorrelation between the remainder 
of the model;

- VIF (variance inflation factor) test: to test the degree of any multicollinearity issue among the independent variables.

\subsection{Statistical Analysis and Hypothesis Testing}

Statistical analysis and hypothesis testing included ensuring the validity and reliability of the study tool, descriptive statistics for the study variables, and the study of the relations between the variables to verify the study hypotheses, as follows.

The validity and reliability of the survey questionnaire: as a data collection tool, were validated using the Cronbach alpha test. The internal consistency of the survey questionnaire statements was tested by calculating the correlation coefficient between each and the global average. The following Table 2 shows the values obtained for internal consistency, and the values of the reliability and validity coefficient of the survey questionnaire responses.

Table 2 shows that the correlation coefficients were found to range between 0.477 and 0.808 and to all be positive at the 0.01 level of significance, which indicates the internal consistency of the responses, whereby the validity coefficient was found to range between 0.646 and 0.894 , and the value of alpha "stability coefficient" was found to be 0.852 , which indicates high consistency and supports the study tool's reliability, which amounted to 0.923 , thus being higher than the acceptable threshold of $60 \%$. This indicates that the responses were reliable and consistent.

Table 2. Internal consistency, reliability, and validity of the survey questionnaire responses.

\begin{tabular}{|c|c|c|}
\hline Statements & $\begin{array}{l}\text { Internal Consistency Test } \\
\text { (Correlation Coefficient) }\end{array}$ & Validity Coefficient ${ }^{(1)}$ \\
\hline Size \& Nature of the Organization \& Its Branches & $0.789^{* *}$ & 0.882 \\
\hline Characteristics \& Size of the Branch Operations & $0.591^{* *}$ & 0.743 \\
\hline Experience \& Personal Judgment & $0.800^{* *}$ & 0.889 \\
\hline Branch Internal Audit Reports & $0.574^{* *}$ & 0.729 \\
\hline Previous External Audit Reports & $0.569^{* *}$ & 0.725 \\
\hline Professional Judgment in Team Guidance & $0.555^{* *}$ & 0.714 \\
\hline Resources Available to Perform Audit & $0.808^{* *}$ & 0.894 \\
\hline Estimated Risks Associated with the Branch Operations & $0.675^{* *}$ & 0.806 \\
\hline Materiality of the Branch Operations & $0.477^{* *}$ & 0.646 \\
\hline Audit Cost & $0.736^{* *}$ & 0.848 \\
\hline Test Cronbach Alpha & 0.852 & \\
\hline Number of Statements & 10 & \\
\hline Reliability Coefficient & 0.923 & \\
\hline
\end{tabular}

${ }^{*}$ : Significant at the 0.01 level; ${ }^{(1)}$ : Validity coefficient $=2 * \mathrm{R} /(1+\mathrm{R})$. 
Confirmatory Factor Analysis (CFA) was used to ensure that the responses measured the study's general axis. Figure 2 shows the CFA results of the factors affecting audit planning in multi-branch organizations. The following Table 3 shows all factors were significant at 0.001 level.

Descriptive analysis of the factors affecting audit planning in multi-branch organizations:

The means of the opinions expressed by our respondents were calculated on the factors affecting audit planning in multi-branch organizations. This was done to determine the influence of these factors, while the standard deviation of the opinions was determined to identify the degree of dispersion of the responses. The results are presented in Table 4.

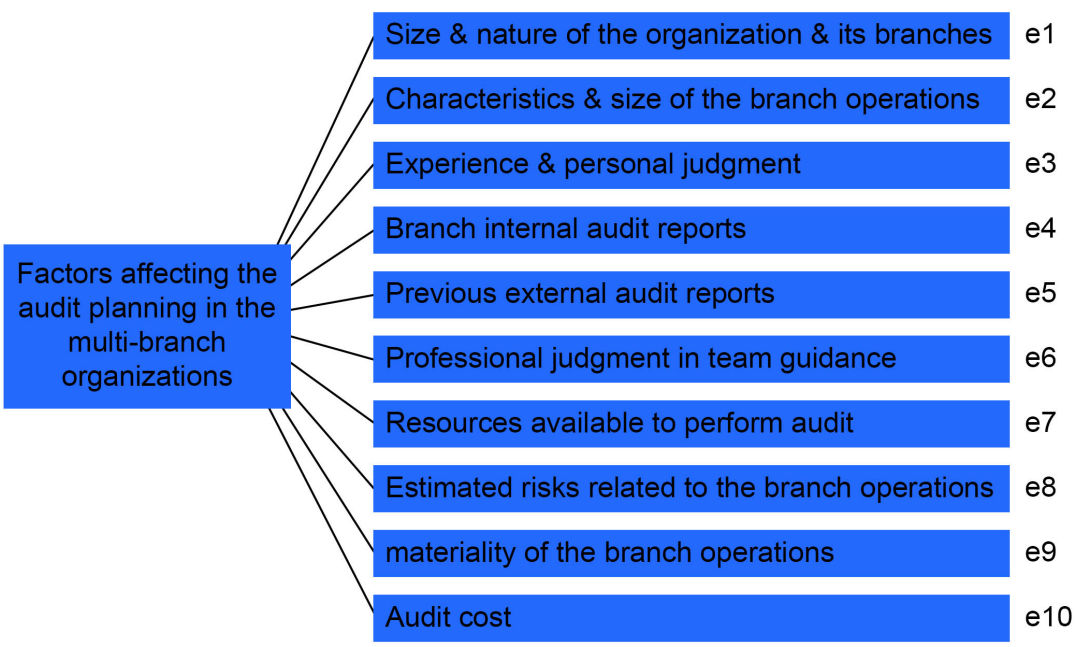

Figure 2. The result of Confirmatory Factor Analysis (CFA).

Table 3. Results of the analysis of factors affecting audit planning in multi-branch organizations.

\begin{tabular}{|c|c|c|c|c|c|c|}
\hline \multirow[t]{2}{*}{$\begin{array}{c}\text { Significance Level } \\
\text { P-Value }\end{array}$} & \multirow[t]{2}{*}{$\begin{array}{c}\text { Critical Value } \\
\text { C.R. }\end{array}$} & \multirow[t]{2}{*}{$\begin{array}{l}\text { Standard Error } \\
\text { S.E. }\end{array}$} & \multirow{2}{*}{$\begin{array}{c}\text { Estimated } \\
\text { Value }\end{array}$} & \multicolumn{3}{|c|}{ Variables } \\
\hline & & & & F1 & $<---$ & $\mathrm{X} 1 \_01$ \\
\hline$* * *$ & 3.938 & 0.171 & 0.672 & $\mathrm{~F} 1$ & $<---$ & $\mathrm{X} 1 \_02$ \\
\hline$* * *$ & 6.277 & 0.166 & 1.042 & $\mathrm{~F} 1$ & $<---$ & X1_03 \\
\hline$* * *$ & 4.384 & 0.182 & 0.796 & F1 & $<---$ & X1_04 \\
\hline$* * *$ & 4.081 & 0.175 & 0.715 & F1 & $<---$ & X1_05 \\
\hline$* * *$ & 4.396 & 0.169 & 0.741 & F1 & $<---$ & X1_06 \\
\hline$* * *$ & 6.191 & 0.194 & 1.201 & F1 & $<---$ & $\mathrm{X} 1 \_07$ \\
\hline$* * *$ & 4.681 & 0.187 & 0.878 & F1 & $<---$ & $\mathrm{X} 1 \_08$ \\
\hline 0.008 & 2.666 & 0.205 & 0.547 & F1 & $<---$ & X1_09 \\
\hline$* * *$ & 4.991 & 0.219 & 1.091 & F1 & $<---$ & $\mathrm{X} 1 \_10$ \\
\hline
\end{tabular}

Note: ${ }^{* * *}$ Significance at the level 0.001 . 
Table 4 shows that the general average of our respondent's opinions amounted to 3.65 , which indicates a high influence of the factors. These were found to vary in terms of their effect, ranging from high to neutral.

The following factors were found to have a high influence, as the average responses ranged from 4.00 to 4.15 . The details are as follows:

- The "estimated risks associated with branch operations" had the highest average response (4.15), which indicates a relative average of $83.0 \%$, with a standard deviation of 1.00. This point at the need to follow scientific methods in risk management;

- Then came "the size and nature of the organization and its branches", with an average response of 4.09 - a relative average thus amounting to $81.8 \%$ - and a standard deviation of 0.94 ;

- Third was "characteristics and size of branch operations", as the average responses measured 4.02 -indicating a relative average of $80.4 \%$ - with a standard deviation of 0.90 ;

- Fourth came "materiality of the branch operations" with an average response of 4.00 - i.e., a relative average of $80.0 \%$ - and a standard deviation of 1.08 ;

- In fifth position was "experience and personal judgment", as the average response was 3.65 - which indicates a relative average of $73.0 \%$ - and the standard deviation 0.89 .

Table 4. Views of the sample on the factors affecting audit planning in multi-branch organizations.

\begin{tabular}{|c|c|c|c|c|c|c|}
\hline Factors & $\begin{array}{l}\text { Arithmetic } \\
\text { mean }\end{array}$ & $\begin{array}{c}\text { relative } \\
\text { weight } \%\end{array}$ & $\begin{array}{l}\text { Standard } \\
\text { deviation }\end{array}$ & $\begin{array}{c}\text { Variation } \\
\text { coefficient } \%\end{array}$ & Impact & Rank \\
\hline Size \& nature of the organization \& its branches & 4.09 & 81.8 & 0.94 & 23.0 & High & 2 \\
\hline Characteristics \& size of the branch operations & 4.02 & 80.4 & 0.90 & 22.5 & High & 3 \\
\hline Experience \& personal judgment & 3.65 & 73.0 & 0.89 & 24.3 & High & 5 \\
\hline Branch internal audit reports & 3.11 & 62.2 & 0.96 & 31.0 & Neutral & 10 \\
\hline Previous external audit reports & 3.30 & 66.0 & 0.93 & 28.1 & Neutral & 8 \\
\hline Professional judgment in team guidance & 3.59 & 71.8 & 0.89 & 24.9 & High & 6 \\
\hline Resources available to perform audit & 3.23 & 64.6 & 1.04 & 32.0 & Neutral & 9 \\
\hline $\begin{array}{l}\text { Estimated risks associated with the branch opera- } \\
\text { tions }\end{array}$ & 4.15 & 83.0 & 1.00 & 24.0 & High & 1 \\
\hline materiality of the branch operations & 4.00 & 80.0 & 1.08 & 27.0 & High & 4 \\
\hline Audit cost & 3.41 & 68.2 & 1.16 & 34.1 & High & 7 \\
\hline Overall average & 3.65 & 73.1 & 0.64 & 17.6 & High & \\
\hline
\end{tabular}


- Sixth was "professional judgment in team guidance", as the average responses was 3.59-a relative average of $71.8 \%$-with a standard deviation of 0.89 ;

- Seventh, and last among the factors with high influence, was "audit cost", with an average response of 3.41-indicating a relative average of $68.2 \%$ - and a standard deviation of 1.16 .

The following factors were of a neutral (medium) degree of influence, as the average response was found to range between 3.11 and 3.30. The details are as follows (Figure 3, Figure 4):

- First, "previous external audit reports", with an average response of 3.30-a relative average amounting to $66.0 \%$-and a standard deviation of 0.93 .

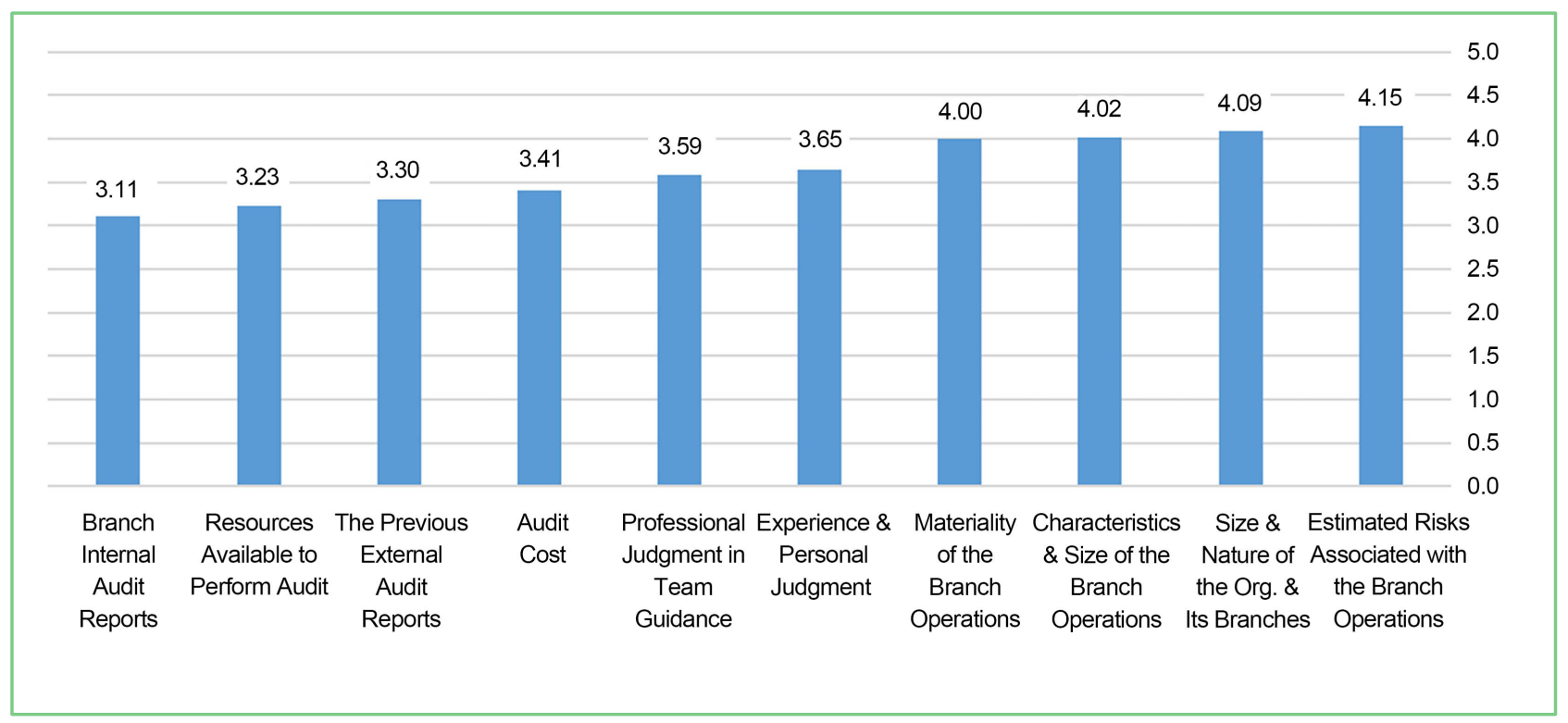

Figure 3. The average responses we received in relation to the factors affecting audit planning in multi-branch organizations.

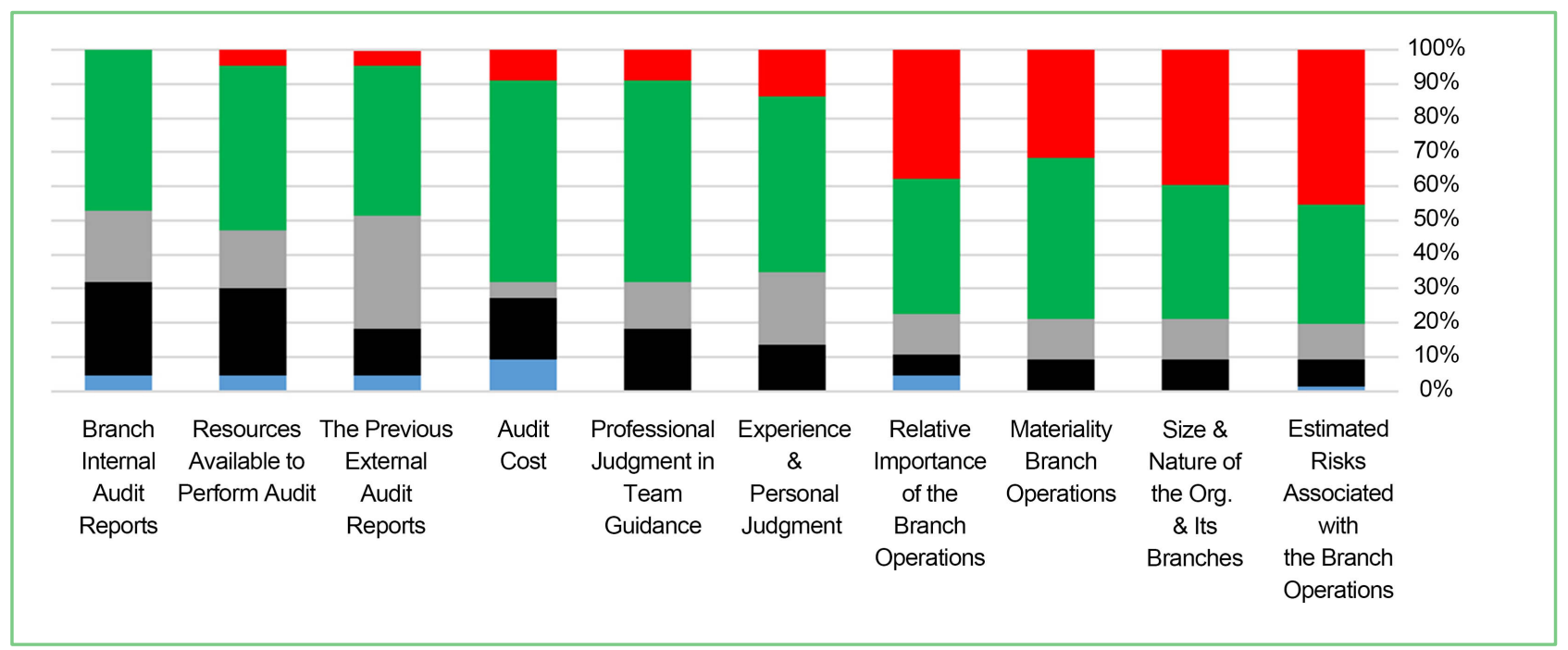

Figure 4. The relative frequencies of the responses received regarding the factors affecting audit planning in multi-branch organizations, arranged according to their importance from the point of view of our respondents. 
- Second, "available resources to perform audit", with an average response of 3.23 - i.e., a relative average amounting to $64.6 \%$ - and a standard deviation of 1.04 .

- Third and last, "branch internal audit reports", with an average response of 3.11 - indicating a relative average amounting to $62.2 \%$ - and a standard deviation of 0.96 .

Results of the 1-sample $\mathrm{T}$ test for the factors affecting audit planning in multi-branch organizations: Table 5 shows that the $\mathrm{T}$ value was 8.256 with a significance level of less than 0.05 , which indicates that the arithmetic mean of the responses is significantly different from the mean value-i.e., significantly higher than the mean value, as the $\mathrm{T}$ value is positive, which indicates the significance of the effect of these factors. The difference ranged between $0.496 \& 0.813$, with an average of 0.646 , and this range did not include zero, which indicates the significance of the difference.

The results of the Mann-Whitney $U$ test of the factors affecting audit planning in multi-branch organizations by type.

Table 6 shows that the $Z$ value of the Mann-Whitney test was found to be -1.362 , with a significance level of $0.173-$ i.e., greater than 0.05 , which indicates the lack of significance of the differences between male and female responses regarding the factors affecting audit planning in multi-branch organizations.

Kruskal-Wallis test results for the factors affecting audit planning in multibranch organizations by position.

Table 7 shows that the value of the chi square for the Kruskal-Wallis test was 24.716 , with a level of significance lower than 0.05 , which indicates statistically significant differences among the sample responses by position. Those were ranked according to the average rating of responses as follows.

First came external auditor, with an average of 47.35; followed by internal auditor, with an average of 44.5 , and by chartered accountant with an average of 37.92. This may be due to the fact that those who hold these positions carry out the audit process from a practical standpoint. Financial market institutions inspector ranked fourth, with an average of 29.83. Internal audit manager came fifth, with an average response rate of 28.35, while financial director came sixth, with an average of 15.5. This may be due to the fact that those who hold these positions carry out audits from a supervisory point of view. Last came assistant

Table 5. The results of 1-sample $\mathrm{T}$ test for the factors affecting the audit planning in the multi-branch organizations.

\begin{tabular}{|c|c|c|c|c|c|c|c|}
\hline Arithmetic Mean & Standard Deviation & Standard Error & T Value & Significance Level & Average Difference & Min. & Max. \\
\hline 3.65 & 0.644 & 0.079 & 8.256 & 0.000 & 0.646 & 0.496 & 0.813 \\
\hline
\end{tabular}

Table 6. The results of the Mann-Whitney $U$ test of the factors affecting audit planning in multi-branch organizations by type.

\begin{tabular}{ccccc}
\hline Gender & No. of Cases & Mean Rank & Mann-Whitney U Test Z & Sig. Level \\
\hline Males & 51 & 35.24 & -1.362 & 0.173 \\
Females & 15 & 27.60 & & \\
\hline
\end{tabular}


Table 7. Kruskal-Wallis test results for the factors affecting audit planning in multi-branch organizations by position.

\begin{tabular}{|c|c|c|c|c|}
\hline Professions & No. of Cases & Mean Rank & Kruskal-Wallis Test Chi Square & Sig. Level \\
\hline Internal Audit Manager & 20 & 28.35 & & \\
\hline Financial Manager & 5 & 15.50 & & \\
\hline External Auditor & 20 & 47.35 & & \\
\hline Internal Auditor & 3 & 44.50 & 24.716 & 0.000 \\
\hline Chartered Accountant or Financial Controller & 6 & 37.92 & & \\
\hline Financial Market Institutions Inspector & 6 & 29.83 & & \\
\hline Assistant Auditor & 6 & 13.25 & & \\
\hline
\end{tabular}

auditor, with an average rating of 13.25 . This is because the assistant auditor performs auxiliary functions.

Kruskal-Wallis test results for the factors affecting audit planning in multibranch organizations by years of experience

Table 8 shows that the value of chi square for the Kruskal-Wallis test reached 10.292 with a level of significance lower than 0.05 , which indicates that there are statistically significant differences between the sample responses about the factors affecting audit planning in multi-branch organizations according to years of experience.

Table 8. Kruskal-Wallis test results for factors affecting audit planning in the multi-branch organizations by the years of experience.

\begin{tabular}{ccccc}
\hline Years of Experience & No. of Cases & Mean Rank & Kruskal-Wallis Test Chi Square & Sig. Level \\
\hline Less than One Year & 3 & 2.00 & 10.292 & 0.016 \\
1 to 5 Years & 9 & 36.94 & \\
6 to 10 Years & 18 & 39.36 & 32.33 & \\
More than 10 Years & 36 &
\end{tabular}

\subsection{Testing the Validity of Hypotheses}

To test the validity of our hypotheses, we performed a 1-Sample test, Correlation Analysis, and Multiple Regression Analysis, and the results were as follows.

1) 1-sample $\mathrm{T}$ test results.

The following Table 9 shows the results of the 1-sample $\mathrm{T}$ test for the mean value:

\subsubsection{The Influence of Experience and Personal Judgment on Audit Planning}

The $\mathrm{T}$ Value was found to be 5.967, with a significant level lower than 0.05 . This indicates that the arithmetic mean of the responses was significantly higher than the average value, pointing at the significance of the effect. The difference ranged between 0.43 and 0.87 , with an average of 0.652 , and this range did not include the zero value, confirming the significance of the difference. Auditor experience and personal judgment is thus statistically significantly correlated audit planning, which supports hypothesis $\mathrm{H} 1$. 
Table 9. 1-sample T test results for mean value.

\begin{tabular}{cccccccc}
\hline Factor & Arithmetic Mean & $\begin{array}{c}\text { Standard } \\
\text { Deviation }\end{array}$ & T Value & $\begin{array}{c}\text { Significance } \\
\text { Level }\end{array}$ & $\begin{array}{c}\text { Average } \\
\text { Difference }\end{array}$ & Min. & Max. \\
\hline $\begin{array}{c}\text { Experience \& Personal Judgment } \\
\text { Materiality of the Branch }\end{array}$ & 3.65 & 0.886 & 5.967 & 0.000 & 0.652 & 0.43 & 0.87 \\
$\begin{array}{c}\text { Operations for the Auditor } \\
\begin{array}{c}\text { Estimated Risks Associated } \\
\text { with the Branch Operations }\end{array}\end{array}$ & 4.00 & 1.081 & 7.513 & 0.000 & 1.000 & 0.73 & 1.27 \\
$\quad$ & 4.15 & 0.996 & 9.392 & 0.000 & 1.152 & 0.91 & 1.40 \\
Audit Cost & 3.41 & 1.163 & 2.857 & 0.000 & 0.409 & 0.12 & 0.70 \\
\hline
\end{tabular}

\subsubsection{The Effect of the Materiality Branch Operations, As Perceived by} the Auditors, on Audit Planning

The $T$ value was 7.513, with a level of significance lower than 0.05 . This indicates that the arithmetic mean of the responses is significantly higher than the average value. The difference ranged between 0.73 and 1.27, with an average of 1.000. This range does not include the zero value, which confirms the significance of that difference. The materiality of branch operations, as perceived by the auditor, is thus statistically significantly correlated with the audit planning. This supports hypothesis $\mathrm{H} 2$.

The effect of the estimated risk associated with branch operations on audit planning. The $\mathrm{T}$ value was 9.392 , with a level of significance lower than 0.05 , which indicates that the arithmetic mean of the responses was significantly higher than the average value. This indicates the significance of the effect, as the average difference was found to range between 0.91 and 1.40, with an average of 1.152. The fact that the range does not include the zero value confirms that the estimated risk associated with branch operations has a statistically significant effect on audit planning. This supports hypothesis H3.

\subsubsection{The Effect of Audit Cost on Audit Planning}

The $\mathrm{T}$ value was 2.857 with a level of significance lower than 0.05 , which indicates that the arithmetic mean of the responses is significantly higher than the average value. The difference was found to range between 0.12 and 0.70 , with an average of 0.409 . As this range does not include the zero value, it confirms that audit planning is statistically significantly influenced by its related cost. This supports hypothesis.

2) Correlation analysis: The following Table 10 shows the correlation matrix between variables:

Table 11 shows:

- A positive, direct, and statistically significant correlation at the 0.01 level between experience and personal judgment, and audit planning, as the correlation coefficient was found to be 0.8 , which confirms the validity of $\mathrm{H} 1$;

- A positive, direct, and statistically significant correlation at the 0.01 level between the estimated risks associated with branch operations and audit planning, as the correlation coefficient was found to be 0.675 , which confirms the validity of $\mathrm{H} 2$; 
Table 10. Correlation matrix between variables.

\begin{tabular}{|c|c|c|c|c|c|}
\hline Factor & $\begin{array}{c}\text { Experience \& } \\
\text { Personal Judgment }\end{array}$ & $\begin{array}{l}\text { Estimated Risks } \\
\text { Associated with the } \\
\text { Branch Operations }\end{array}$ & $\begin{array}{c}\text { Relative Importance } \\
\text { of the Branch } \\
\text { Operations }\end{array}$ & $\begin{array}{l}\text { Audit } \\
\text { Cost }\end{array}$ & $\begin{array}{c}\text { Audit } \\
\text { Planning }\end{array}$ \\
\hline Experience \& Personal Judgment & 1 & & & & \\
\hline $\begin{array}{l}\text { Estimated Risks Associated with the } \\
\text { Branch Operations }\end{array}$ & 0.567 & 1 & & & \\
\hline Materiality of the Branch Operations & 0.209 & 0.300 & 1 & & \\
\hline Audit Cost & 0.514 & 0.490 & 0.391 & 1 & \\
\hline Audit Planning & 0.800 & 0.675 & 0.477 & 0.736 & 1 \\
\hline
\end{tabular}

Table 11. Multiple regression analysis results between the dependent and independent variables.

\begin{tabular}{|c|c|c|c|c|}
\hline \multicolumn{5}{|c|}{ Audit Planning Y Dependent Variable } \\
\hline \multirow{2}{*}{ Independent Variables } & \multirow{2}{*}{ Regression Coefficients } & \multicolumn{2}{|c|}{ Operation Sig. Tests } & \multirow{2}{*}{ VIF } \\
\hline & & T Test & Sig. & \\
\hline Regression Constant & 0.793 & 4.500 & 0.000 & \\
\hline X03 Experience \& Personal Judgment & 0.359 & 7.569 & 0.000 & 1.656 \\
\hline X08 Estimated Risks Associated with the Branch Operations & 0.118 & 2.811 & 0.007 & 1.633 \\
\hline X09 Materiality of the Branch Operations & 0.117 & 3.519 & 0.001 & 1.206 \\
\hline X10 Audit Cost & 0.175 & 4.917 & 0.000 & 1.616 \\
\hline
\end{tabular}

Corrected determination coefficient adjusted $\mathrm{R}$ square $=0.833$; Model F sig. test $=82.225$; Sig. Level $=0.000$; Autocorrelation test D.W Durbin-Watson $=1.892$.

- A positive, direct, and statistically significant correlation at the 0.01 level between materiality of branch operation-as perceived by auditors-and audit planning, as the correlation coefficient was found to be 0.477 , which confirms the validity of $\mathrm{H} 3$;

- A positive, direct, and statistically significant correlation at the 0.01 level between audit cost and audit planning, as the correlation coefficient was found to be 0.736 , which confirms the validity of $\mathrm{H} 4$.

3) Multiple regression results were as follows:

The regression equation took the following form:

$$
Y=0.793+0.359 * X 03+0.118^{*} X 08+0.117 * X 09+0.175 * X 10+\varepsilon
$$

where:

$Y$ audit planning (dependent variable);

$X 03$ experience \& personal judgment;

$X 08$ estimated risks associated with branch operations;

X09 relative importance of branch operations;

$X 10$ audit cost.

The model showed that the independent variables affect the dependent one $-Y$ "audit planning"-as follows:

- The variable $X 03$ "experience and personal judgment" has a positive effect, as a unitary increase in experience and personal judgment leads to a 0.359 unit increase in audit planning; 
- The variable $X 08$ "estimated risks associated with the branch operations" has a positive effect, as a unitary increase in the estimated risks associated with branch operations leads to a 0.117 unit increase in audit planning;

- The variable $X 09$ "materiality of the branch operations" has a positive effect, as a unitary increase in the materiality of the branch operations leads to a 0.118 unit increase in audit planning;

- The variable $X 10$ "audit cost" has a positive effect, as a unitary increase in audit cost leads to a 0.175 unit increase in audit planning.

Model significance test and estimated coefficients (model validity): according to the (F) test, the model significance as a whole was confirmed at the 0.000 level of significance, as the $\mathrm{F}$ value was found to be 82.225 with a 0.000 level of significance, which confirms the significance of the model at the 0.01 level of significance. The significance of the estimated parameters was also confirmed, as the level of significance of the T test was less than 0.01 for all of them, and this is one of the characteristics of the Stepwise Regression model that it is satisfied with the variables with a significant effect only.

Matching quality test (model explanatory power): the value of the model's coefficient of determination R2 was found to be approximately 0.833 , meaning that the explanatory variables explain $83.3 \%$ of the changes occurring in the dependent variable. This indicates the high explanatory power of the model.

\subsection{Requirements for the Application of the Artificial Ant Algorithm}

The C\# programming language has been used to write a computer program to implement the ant algorithm using hypothetical data from the answers to the questionnaire.

When applying the ant algorithm to audit planning, we assumed:

1) The presence of a group of external auditors representing an agent;

2) A group of branches representing the nodes;

3) Audit risk and materiality are the two main components of the ant algorithm;

4) The descriptive assessment of audit risk has been converted into a numerical assessment as follows: high ( $100 \%$ to $75 \%$ ), medium (less than $75 \%$ to $50 \%$ ), low (less than 50\%).

The program succeeded in determining the optimal path for external auditors on the various branches, thus rationalizing personal judgment. Better results can be achieved when applying to a larger number of branches (Table 12).

Table 12. Ant algorithm output.

\begin{tabular}{llllllllll}
\hline Reviewer No.: 0 & 3 & 6 & 5 & 7 & 2 & 8 & 1 & 9 & 4 \\
Reviewer No.: 1 & 9 & 4 & 2 & 8 & 7 & 5 & 0 & 3 & 6 \\
Reviewer No.: 2 & 8 & 4 & 1 & 9 & 0 & 3 & 6 & 5 & 7 \\
Reviewer No.: 3 & 0 & 6 & 5 & 7 & 2 & 8 & 1 & 9 & 4 \\
Reviewer No.: 4 & 1 & 9 & 9 & 8 & 7 & 5 & 0 & 3 & 6 \\
\hline
\end{tabular}




\section{Conclusion and Recommendation}

Available literature and data analysis have revealed that:

1) Most of the sample respondents believe that practical experience and personal judgment play a major role in planning the audit process in multi-branch organizations, and that this is due to the difficulty of using a quantitative method;

2) The audit risks and the materiality of the branch operations are among the most important elements that the auditor takes into consideration when setting the audit schedule;

3) The use of the ant algorithm helps determine the optimal path for each auditor on the different branches, thus rationalizing the personal judgment.

In the light of the findings, to improve the planning process of audits in multi-branch organizations, we suggest:

- The training of external audit practitioners should be conducted based on modern scientific and technological methods;

- Implementation of AI methods helps reduce bias and judgment of auditors;

- The ant algorithm could be applied to other audit aspects, such as the distribution of auditors under different restrictions;

- The three-dimensional ant algorithm should be expanded, as it can deal with big data;

- Specialized experts and consultants should be employed to deal with the difficulties that may arise from the application of AI methods;

- Seminars and conferences should be held to disseminate knowledge about modern methods in the field of audit planning.

\section{Conflicts of Interest}

The authors declare no conflicts of interest regarding the publication of this paper.

\section{References}

AICPA (American Institute of Certified Public Accountants) (2019). Codification of Statements on Auditing Standards. American Institute of Certified Public Accountants. https://doi.org/10.1002/9781119646365

Ashton, A. H. (1991). Experience and Error Frequency Knowledge as Potential Determinants of Audit Expertise. The Accounting Review, 66, 218-239.

Bani-Ahmed, A., \& Al-Sharairi, J. (2014). The Relationship between Planning of Audit Process and Total Quality Management. International Journal of Business and Management, 9, 96-105. https://doi.org/10.5539/ijbm.v9n5p96

Bertelle, C., Dutot, A., Guinand, F., \& Olivier, D. (2003). Colon Ant Population Algorithm for Dynamic Distribution in Simulation. Universite du Havre.

Bonner, S. (1990). Experience Effects in Auditing: The Role of Task-Specific Knowledge. The Accounting Review, 65, 72-92.

Bowling, S. (2019). How We Successfully Implemented AI in Audit. Journal of Accountancy, 227, 26-28. 
Castro, C. D. (2006). A Survey on Using Ant Based Techniques for Clustering. http://www.semanticscholar.org

Coppin, B. (2004). Artificial Intelligence Illuminated. Jones Bartlett Inc.

Dorigo, M., \& Gambardella, L. M. (1997). Ant Colony System: A Cooperative Approach to the Travelling Salesman Problem. IEEE Transactions on Evolutionary Computation, 1, 53-66. https://doi.org/10.1109/4235.585892

Erdinc, O. (2017). Optimization in Renewable Energy-Recent Perspective. Elsevier, Ltd.

Gao, W. (2016). Improved Ant Colony Clustering Algorithm And its Performance Study. Computational Intelligence and Neuroscience, 2016, Article ID: 4835932. https://doi.org/10.1155/2016/4835932

IFAC (International Federation of Automatic Control) (2009). International Standard on Auditing (ISA) 300. http://www.ifac.org

Issa, H. (2016). Research Ideas for Artificial Intelligence in Auditing: The Formalization of Audit and Workforce Supplementation. Journal of Emerging Technologies in Accounting, 13, 1-20. https://doi.org/10.2308/jeta-10511

Jafar, O. A. M., \& Sivakumar, R. (2010). Ant-Based Clustering Algorithms: A Brief Survey. International Journal of Computer Theory and Engineering, 2, 787-796. https://doi.org/10.7763/IJCTE.2010.V2.242

Johnstone, K. M., \& Bedard, J. C. (2003). Risk Management in Client Acceptance Decisions. The Accounting Review, 78, 1003-1025. https://doi.org/10.2308/accr.2003.78.4.1003

Jones, M. T. (2006). Artificial Intelligence Application Programming. Dreamtech Press.

Karapetrovic, W. E. S. (2010). Audit System: Concepts and Practices. Total Quality Management, 12, 13-18. https://doi.org/10.1080/09544120020010066

Leung, P. C. P. (2015). Modern Auditing. John Wiley \& Sons.

Meliyev, I. I. (2017). Impact of Audit Planning Quality: Case Study of Local Audit Firm in Uzbekistan. International Journal of Economics, Commerce and Management, 5, 379385.

Pop, P. C., Pintea, C.-M., \& Dumitrescu, D. (2009). An Ant Colony Algorithm for Solving The Dynamic Generalized Vehicle Routing Problem. Dynamical Systems and Applications, 1, 373-382.

PWC (2019, August). PWC Completes its First Stock Count Audit Using Drone Technology.

https://www.commercialdroneprofessional.com/pwc-uses-drone-to-complete-a-stockcount-audit-for-the-first-time/

SOCPA (Saudi Organization for Chartered and Professional Accountant) (2018). A Guide to the Practice of Auditing in the Kingdom of Saudi Arabia.

http://www.socpa.org.sa

Solomon, I. (1996). Industry Specialization, Business Operations Knowledge and Auditor Judgment: an Experimental Investigation. University of Illinois.

Taylor, M. (2010). The Effect of Industry Specialization Auditors Inherent Risk Assessments and Confidence Judgements. Contemporary Accounting Research, 17, 693-712. https://doi.org/10.1506/3LDH-AV52-0F4W-H4BB

Vizine, A. L., de Castro, L. N., Hruschka, E. R., \& Gudwin, R. R. (2005). Towards Improving Clustering Ants: An Adaptive Clustering Algorithm. Informatica, 29, 143-145.

Wikipedia (2021). Swarm Intelligence. https://en.wikipedia.org/wiki/Swarm intelligence 
Wright, S., \& Wright, A. M. (1997). The Effect of Industry Experience on Hypothesis Generation and Audit Planning Decisions. Behavioral Research in Accounting, 9, 273-299.

https://doi.org/10.2139/ssrn.42913 